\title{
Methodology for determining multilayered temperature inversions
}

\author{
G. J. Fochesatto \\ Department of Atmospheric Sciences, Geophysical Institute and College of Natural Science and Mathematics, \\ University of Alaska Fairbanks, 903 Koyukuk Dr., Fairbanks, Alaska 99775, USA
}

Correspondence to: G. J. Fochesatto (foch@gi.alaska.edu)

Received: 6 September 2014 - Published in Atmos. Meas. Tech. Discuss.: 16 October 2014

Revised: 7 April 2015 - Accepted: 8 April 2015 - Published: 11 May 2015

\begin{abstract}
Temperature sounding of the atmospheric boundary layer $(\mathrm{ABL})$ and lower troposphere exhibits multilayered temperature inversions specially in high latitudes during extreme winters. These temperature inversion layers are originated based on the combined forcing of local- and large-scale synoptic meteorology. At the local scale, the thermal inversion layer forms near the surface and plays a central role in controlling the surface radiative cooling and air pollution dispersion; however, depending upon the large-scale synoptic meteorological forcing, an upper level thermal inversion can also exist topping the local ABL.

In this article a numerical methodology is reported to determine thermal inversion layers present in a given temperature profile and deduce some of their thermodynamic properties.

The algorithm extracts from the temperature profile the most important temperature variations defining thermal inversion layers. This is accomplished by a linear interpolation function of variable length that minimizes an error function. The algorithm functionality is demonstrated on actual radiosonde profiles to deduce the multilayered temperature inversion structure with an error fraction set independently.
\end{abstract}

\section{Introduction}

The atmospheric boundary layer (ABL) is the lowest part of the troposphere in permanent contact with the earth surface and responds to thermal and roughness surface forcing in timescales of minutes to hours (Stull, 1988). Synoptic largescale meteorological processes condition the ABL state by driving relatively rapid horizontal air mass exchange for example under a cyclonic air mass advection (Fochesatto et al., 2002) or simply by imposing, on upper tropospheric levels, an adiabatic compression through the formation of a highpressure anticyclone (Byers and Starr 1941; Bowling et al., 1968; Curry, 1983; Cassano et al., 2011). These large-scale synoptic processes constrain the temperature of the air mass in tropospheric levels without initial connection to the local surface temperature forming vertically localized positive upward thermal gradients called elevated inversion (EI) layers (Csanady, 1974; Milionis and Davies, 1992, 2008; Mayfield and Fochesatto, 2013).

Although the ABL timescale for surface response ranges from minutes to hours (Garrat and Brost, 1981; Stull, 1988), the ABL response to synoptic forcing at local scale initiated by the radiative and dynamic interaction in the presence of the EIs can vary from hours to several days depending on a number of factors related to topographic conditions, temperature and wind distribution, thermal stratification and synoptic air mass type (e.g., moist cyclone advection or dry anticyclone situations, Mayfield and Fochesatto, 2013).

In polar atmospheres, the surface energy balance during winter is dominated by surface radiative exchange (Shulski and Wendler, 2007; Huff et al., 2010). This exchange occurs between a shallow layer close to the ground capped by the surface-based inversion (SBI) top height. The SBI also plays a thermalizing role in the surface cooling process by promoting radiative equilibrium between surface long-wave emission and the air mass radiative emission contained within the SBI layer depth (Malingowski et al., 2014). The SBI is present normally under non-advective conditions over iceand snow-covered surfaces and is a common feature in continental places as well as in the Arctic Ocean, sea ice and maritime environments (Overland and Guest, 1991; Ueno et al., 2005; Eastman and Warren, 2010; Bintanja et al., 2011). The SBI formation and persistence is also strongly dependent on terrain morphology and orientation (e.g., formation of cold 
pools Mahrt et al., 2001; Clements et al., 2003; Whiteman and Zhong, 2008; Fochesatto et al., 2013). Of particular interest is the formation and breakup of the SBI layer (Billelo, 1966; Hartman and Wendler, 2005), its thermal regime across time as it forms (i.e., fast cooling at the formation process followed by a growing depth phase) (Malingowski et al., 2014) and its thermodynamic characteristics controlling the sensible and latent heat exchange rate (Raddatz et al., 2013a, b). Moreover, simultaneous determination and characterization of EI layers and SBI has the potential to improve assessment on local air pollution meteorology (André and Mahrt, 1982), to improve forecasting of freezing rain episodes (Robbins and Cortinas, 2002), to determine heat exchanges in unconsolidated sea-ice surfaces (Raddatz et al., $2013 \mathrm{a}, \mathrm{b}$ ) and potential impact on subarctic and Arctic climate (Ueno et al., 2005; Eastman and Warren, 2010; Bintanja et al., 2011).

The most widely used instrumentation to observe thermal inversion layers is direct temperature determination by highresolution radiosondes. However the methodologies to analyze the radiosonde temperature profile (see for example Seidel et al., 2010) still do not account for complex embedded thermal structures. On the other hand some authors have classified these layers as being short-living structures and therefore discarded from their analyses (Kahl 1990; Serreze et al., 1992). However, it was recently demonstrated during the Winter Boundary-Layer Experiment (Wi-BLEx) (Fochesatto et al., 2013; Mayfield and Fochesatto, 2013; Malingowski et al., 2014) that complex thermal structures persist with some changes through the day depending on environmental conditions.

Nonetheless, trying to detail more in-depth turbulent mixing processes in the $\mathrm{ABL}$, the observations demand instrumentation that can profile the atmosphere at higher spatial and temporal resolution than what a radiosonde instrument can provide. Thus active remote sensing instruments give a better description of the vertical structure and dynamics of the ABL such as the case for example of lidar (Light Detection And Ranging, Fochesatto et al., 2001a, b, 2004, 2005, 2006) and sodar (SOund Detection And Ranging; Beyrich and Weill, 1993; Fochesatto et al., 2013). Particularly interesting is the high temporal and spatial resolution at which lidars can describe the initiation of convection close to the surface as well as the dynamic of the residual layer (Fochesatto et al., $2001 \mathrm{a}, \mathrm{b})$. Similarly, insightful description of the turbulent and dynamic structure of the ABL when shallow cold flows penetrate the stable ABL can be gained by using sodar profilers (Fochesatto et al., 2013). On the other hand, passive ground-based remote sensors i.e., microwave radiometers, based on background sky microwave radiation sensing are another option to profile the $\mathrm{ABL}$ at $\sim$ minute resolution. Methodologies to determine the ABL height using lidars are based on detecting the changes in the optical backscattering level when the laser beam crosses the interface between the air mass in the ABL and the free troposphere (Menut et al., 1999; Bianco and Wilczak, 2002; Brooks, 2003; Lam- mert and Bosenberg, 2006). However, determining the ABL height using sodar becomes a little more complicated because the observations give access to the temperature structure of turbulence $C_{T}^{2}$ profile that changes depending upon the ABL phase, terrain and multilayer structure (Holmgren et al., 1975; Beyrich and Weill, 1993).

Radiosonde determination of thermal inversion layers to study the Arctic Ocean ABL has been done using function fitting on radiosonde in the Arctic Ocean (Serreze et al., 1992) to determine the large-scale climate signature in the SBI time series of polar regions of the Arctic and Antarctic (Seidel et al., 2010; Zhang and Seidel, 2011; Zhang et al., 2011). In short-term studies, Khal (1990) and Khal et al. (1992) implemented a methodology to explore the temperature profile and then, applying some constraints, deduce the SBI top height, using similar methodologies trying to link time series of SBI heights to large-scale climate processes in continental Alaska (Bourne et al., 2010).

In this article a mathematical procedure is described, and its numerical implementation is documented to determine the multilayer thermal structure present on a given temperature profile in the lower troposphere. Section 2 describes the mathematical procedure and numerical implementation, Sect. 3 determines the calibration factor, Sect. 4 applies the numerical procedure to routine and high-resolution radiosonde observations and Sect. 5 gives a final assessment of the implemented numerical methodology.

\section{Methodology}

A thermal inversion layer represents a region in the atmosphere defining a positive upward temperature gradient $\frac{\mathrm{d} T}{\mathrm{~d} z}>$ 0 , where $T$ is the temperature and $z$ is the height. As described in the Introduction this positive upward temperature gradient can have two origins: the first one related to surface cooling (i.e., surface net radiation loss) giving origin to the formation of the so-called SBI, and the second one originated after synoptic large-scale processes (i.e., upper level warming also known as EI layers) (Mayfield and Fochesatto, 2013). Under these conditions the temperature profile in the lower troposphere is expected to describe either a neutral thermal condition (no inversion present), isothermal layers, presence of a surface-based inversion (SBI), development of stratified layers within the SBI layer depth, shallow inversion layers above the SBI inversion top or more complex situations in which upper-level thermal inversions are also present with base and top in the outflow ABL (Khal, 1990; Mayfield and Fochesatto, 2013). Figure 1 depicts the more relevant situations.

To deduce the existing thermal inversion layers in a temperature profile, a computational routine was implemented to identify the heights and temperatures of the base and top of inversion layers. In this case the temperature profile was reduced to a mathematical expression based on a linear func- 


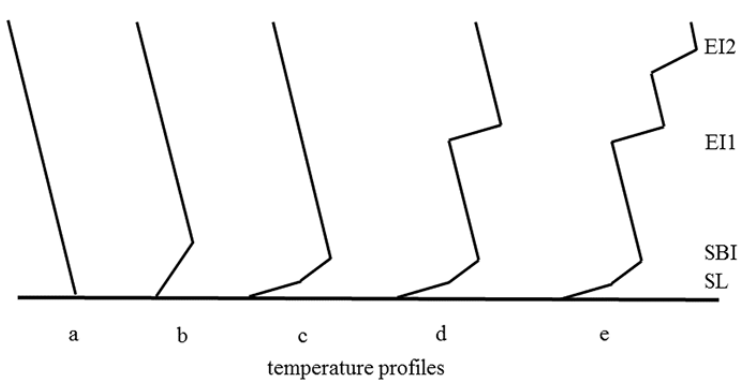

Figure 1. Illustration of temperature profiles indicating different thermodynamics conditions from left to right: (a) no inversion present; (b) presence of an SBI; (c) presence of a stratified SBI; (d) SBI stratified in the presence of an EI and (e) SBI stratified and multiple EIs. Modified after Khal (1990).

tion calculated on the basis of an iterative linear interpolation routine. The numerical routine is based on fitting and refitting a piecewise linear interpolating function with variable length to define layer by layer the temperature profile composition. An error quote controls the algorithm convergence by layer and is calculated based on the largest singular value $\varepsilon$ by which thermal features in the temperature profile can be reproduced. The numerical method actually reduces the number of points present in the original temperature profile. Therefore after applying the numerical methodology, the temperature profile became a data structure defining thermodynamic characteristics of thermal layers found in the temperature profile. Further on, exploring the data structure we can define a thermal inversion layer as the layer in which the temperature gradient turns positive upward to negative upward.

Equation (1) indicates the mathematical formula describing the piecewise linear approximation of the temperature profile:

$\phi(z)=\sum_{k=1}^{N-1} m_{k} \cdot z+b_{k}$,

where $k$ represents each linear interval fitting and $N$ is the total number of temperature measurements. The sequence of linear fitting is executed by selecting two temperature points at the time - one from the top height and the other from bottom height maintaining bottom fixed - until the linear piecewise function minimizes the error quote against the temperature profile as indicated in Eq. (2):

$\varepsilon=\|\phi(z)-T(z)\|$.

Here $\varepsilon$ represents the mathematical norm or Euclidean distance between the linear piecewise mathematical representation $\phi(z)$ and the original temperature profile $T(z)$.

This way the temperature profile is assimilated to the series of sequentially fitted linear intervals defining the temperature function. It has to be noted that after the layer $(k)$ has been detected, the layer $(k+1)$ considers its lowermost point as being the top height of layer $(k)$ and starts over again "connecting" this point with the top-height point of the temperature profile and, from there, descending in height until the $\varepsilon$ value reaches the preset threshold. This way the procedure continues until the entire temperature profile has been scanned and assimilated to frames defined by piecewise linear functions.

Basically the number of piecewise linear functions $(k)$ will be defined by the ultimate number of temperature measurements composing the temperature profile $(N)$; thus $\max (k)=N-1$. However, increasing the error fraction $(\varepsilon)$ will therefore reduce the $\max (k)$ reached. In such a case the final approximation formula is expressed in Eq. (3):

$\phi(z)=\sum_{k=1}^{k=p} m_{k} \cdot z+b_{k}$

where $p$ is the total number of points from the original temperature profile that has been retained by the fitting process.

Table 1 indicates a five-layer temperature structure in the $\mathrm{ABL}$ up to $1 \mathrm{~km}$ height based on six-point temperature simulation. The profile defines a stratified SBI with top height at $250 \mathrm{~m}$ topped by an EI at $670 \mathrm{~m}$. Figure 2 illustrates the sequences in which the algorithm operates to search and define each layer from 1 to 5 . In this case we retain all points in the temperature profile.

\section{Convergence factor}

Since the ability of the algorithm to extract thermal inversion layers depends upon the value chosen for $\varepsilon$, then it is reasonable to determine for example what threshold value of temperature profile gradient $\mathrm{d} T / \mathrm{d} z$ in ${ }^{\circ} \mathrm{C} / 100 \mathrm{~m}$ can be retrieved when a given value of $\varepsilon$ is preset. To deduce this relationship a numerical simulation was performed scanning values of $\varepsilon$ from 0.1 to 20 over a temperature profile displaying a single thermal inversion which was varied in temperature strength $\Delta T$ from 0.1 to $20^{\circ} \mathrm{C}$ and vertical depth $\Delta z$ from 1 to $500 \mathrm{~m}$. For each step on $\varepsilon$ values the temperature gradient threshold $\mathrm{d} T / \mathrm{d} z$, able to determine that specific layer, was deduced.

Figure 3 panel on the left illustrates the simulated temperature inversion and the applied temperature strength and vertical depth variability. Similarly the temperature gradient threshold as a function of the convergence error $\varepsilon$ is shown in Fig. 3 in the panel on the right. This relationship was determined in an ideal scenario of a single temperature inversion layer. Following Fig. 3 (right panel), if a constant inversion layer depth is analyzed (e.g., $\Delta z=200 \mathrm{~m}$ ) and starting on $\varepsilon=20$, the minimum temperature strength across the given layer will be $6.5^{\circ} \mathrm{C} / 100 \mathrm{~m}$ while reducing $\varepsilon=5$ allows detection of $2{ }^{\circ} \mathrm{C} / 100 \mathrm{~m}$; if $\varepsilon=1$ is considered, then the detection limits drop to less than $1{ }^{\circ} \mathrm{C} / 100 \mathrm{~m}$. It has to be noted that $\varepsilon$ is a convergence factor that gives to the algorithm more 

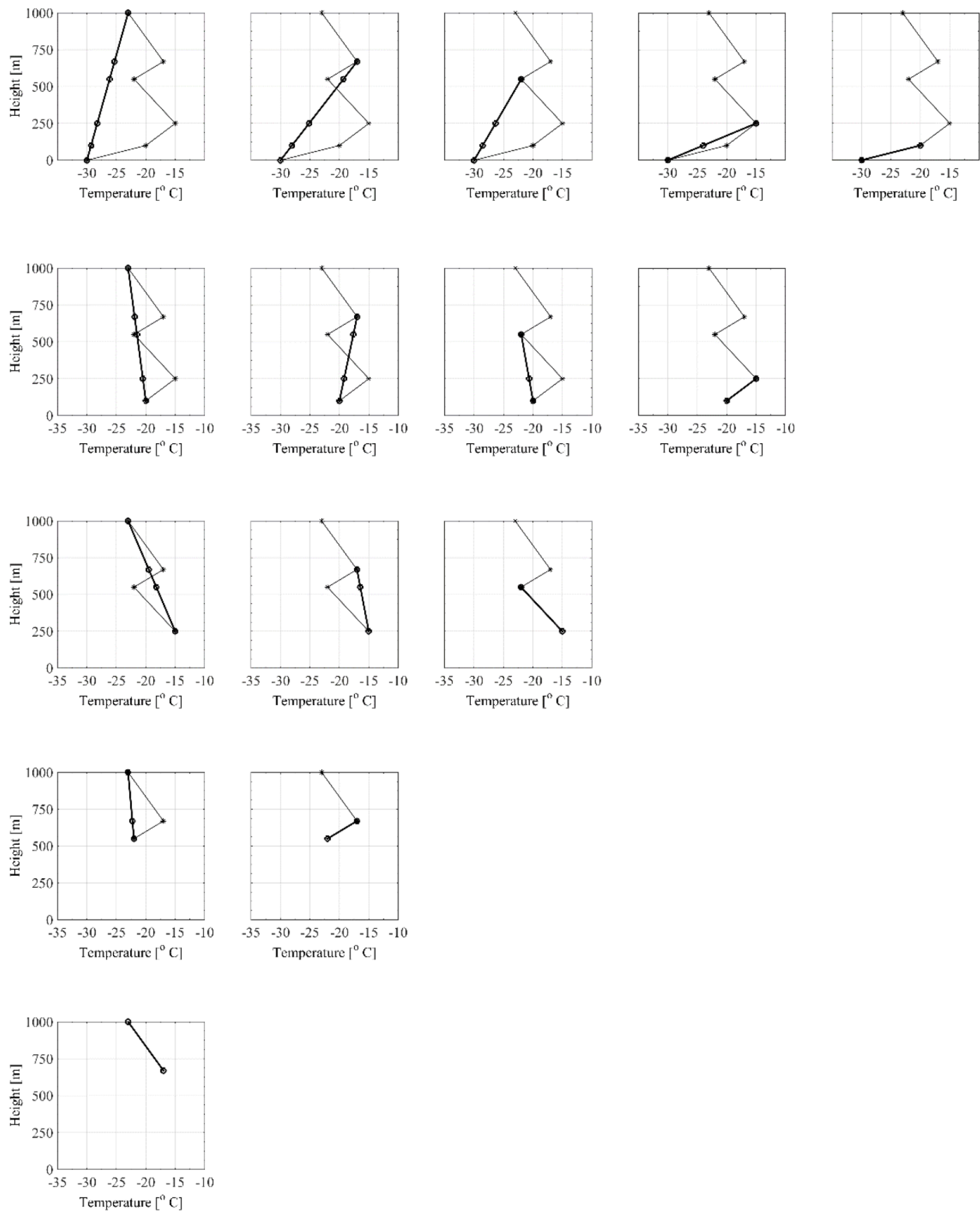

Figure 2. Sequence of the numerical routine to identify the thermal layers indicated in Table 1. Fitting function is given by the thick trace with "o" markers while the temperature profile is indicated by thin black trace with "*" markers. Top panel indicate the sequence to detect Layer 1, second panel from top is sequence to detect Layer 2, third panel from top is the detection of Layer 3, fourth panel from top is to detect Layer 4 and bottom panel is the sequence to determine Layer 5. 
Table 1. Proposed thermal layers in a temperature profile.

\begin{tabular}{lrrrrrl}
\hline Layer & 1 & 2 & 3 & 4 & 5 & Units \\
\hline$T_{\mathrm{t}}, z_{\mathrm{t}}$ & $-20,100$ & $-15,250$ & $-22,550$ & $-17,670$ & $-23,1000$ & ${ }^{\circ} \mathrm{C}, \mathrm{m}$ \\
$T_{\mathrm{b}}, z_{\mathrm{b}}$ & $-30,0$ & $-20,100$ & $-15,-22$ & $-22,550$ & $-17,670$ & ${ }^{\circ} \mathrm{C}, \mathrm{m}$ \\
$\mathrm{d} T / \mathrm{d} z$ & 10 & 3.3 & -2.3 & 4.2 & -1.8 & ${ }^{\circ} \mathrm{C} / 100 \mathrm{~m}$ \\
Class & - & - & $\mathrm{SBI}$ & - & $\mathrm{EI}$ & \\
\hline
\end{tabular}
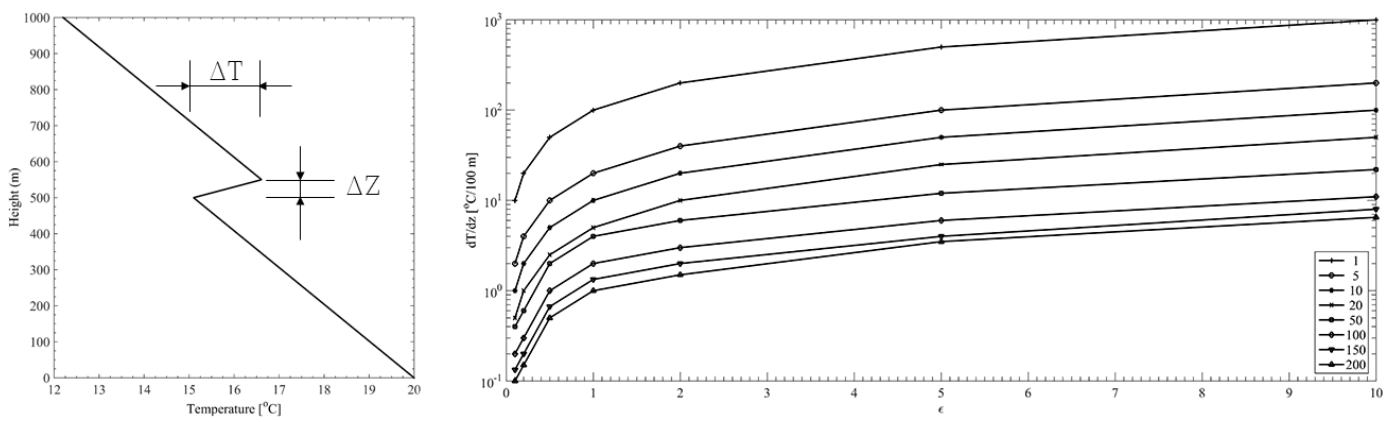

Figure 3. Convergence error simulation: the left panel illustrates the simulated temperature inversion varying $\Delta Z$ in meters and $\Delta T$ in degrees Celsius. Right panel is the minimum thermal gradient detected expressed in ${ }^{\circ} \mathrm{C} / 100 \mathrm{~m}$ on a single inversion layer as function of the preset error norm $\varepsilon$ varying from 0.1 to 20 . The parameter in this curve is the layer depth represented in this case from 1 to $200 \mathrm{~m}$.

or less sensitivity to detect thermal structures present in the given temperature profile.

\section{Numerical application}

In this section the numerical method is applied to the restitution of thermal layers from radiosonde data. Two cases are examined. The first one comes from the radiosonde data archive of NOAA-ESRL database for the Fairbanks International airport WMO station code 70261 retrieved from the Wyoming radiosonde database (http://weather.uwyo.edu/ upperair/sounding.html). The sounding was taken on 15 January 2014 at 00:00 UTC (Fig. 4 - left panel). The second case corresponds to one of the GPS sounding cases taken during an intensive observing period in the framework of Wi-BLEx (Malingowski et al., 2014). In this case a morning sounding was chosen during 13 October 2009 at 15:00 UTC (Fig. 4 right panel) during formation process of the SBI layer.

Table 2 summarizes all retrieved layers extracted presetting $\varepsilon=0.1$. This setting allowed detecting $p=24$ layers over 32 temperature points below $3 \mathrm{~km}$ in the case of 15 January 2014 at 00:00 UTC, while for 13 October 2009 at 15:00 UTC the sounding presents 677 points below $3 \mathrm{~km}$ and $p=56$ layers were detected.

From the analysis of detected layers one can initially search in the data structure the changes in $m_{k} \cdot m_{k}>0$ will be assigned to positive upward $\mathrm{d} T / \mathrm{d} z$, while negative will indicate the opposite. From the analysis of the resulting data it can be deduced that the inversion layer, defined when $m_{k}$ changes from positive to negative, will be assigned as SBI when the base of that inversion is located at the surface, regardless of its stratification condition, while, on the other hand, any other inversion layer with base off the ground will be called EI. In the case of 15 January 2014 at 00:00 UTC, it was found that the SBI top height is located at $165 \mathrm{~m}$ above the ground, while for 13 October 2009 at 15:00 UTC is was located at $44 \mathrm{~m}$ above the ground. On the other hand two EI layers were detected in the first case with inversion top heights at 925 and $1751 \mathrm{~m}$ from the surface. However in the second case a number of EI layers have been identified with top inversion heights at 289, 425, 541, 654, $1098 \mathrm{~m}$, etc. The retrieved thermal inversion SBI and EI layers are summarized in Table 2.

Furthermore, the algorithm performance to extract the multilayered thermal structure was evaluated using the abovementioned examples in terms of the number of layers detected as function of the preset convergence error $\varepsilon$ and the final temperature retrieved error $(\%)$. In this case the algorithm was executed in a loop varying $\varepsilon$ in the interval from 0.1 to 1.0 in steps of 0.1 and from 1.0 to 15 in a 0.5 step. The final temperature error was computed based on the norm of the final temperature vector resampled in terms of the original vector height. This explains why the actual preset value $\varepsilon$, which applies to every step in the fitting and re-fitting process, is different from the final temperature profile error after fitting the entire temperature profile. Figure 5 depicts two curves indicating the number of thermal layers retrieved and the final overall temperature error profile as a function of the $\varepsilon$ preset value for both sounding cases. 

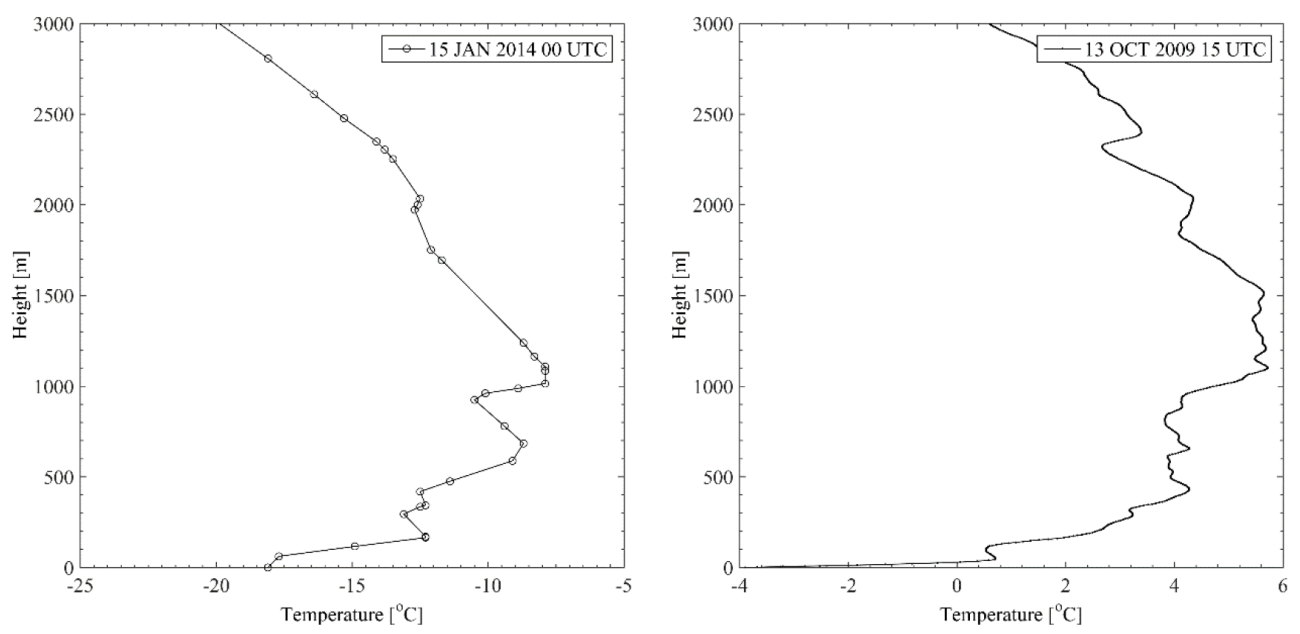

Figure 4. Analysis of radiosonde temperature profile: panel on the left represents temperature observation made on 15 January 2014 at 00:00 UTC and panel on the right is a GPS radiosonde observation during IOP WiBLEx on 13 October 2009 at 15:00 UTC both at the National Weather Service (NWS) Fairbanks International Station (code 70261). Vertical axis is height (m) above ground level.

Table 2. Results of application of the numerical routine to extract thermal layers from radiosonde database NOAA-ESRL PAFA 70261 for 15 January 2014 at 00:00 UTC and IOP WiBLEx GPS sounding on 13 October 2009 at 15:00 UTC. In this case $\varepsilon=0.1$ for both profiles. The temperature profile contains 32 points below $3 \mathrm{~km}$ height and the program detected $p=24$ layers; for 13 October 2009 the sounding contains 677 points below $3 \mathrm{~km}$ and $p=56$ layers. In the classification column, the thermal inversion layers detected are indicated as SBI or EI. First column represents the layer number, second column is the layer base height $Z_{\mathrm{b}}(\mathrm{m})$, third column is the layer top height $Z_{\mathrm{t}}$ (m), fourth column is the temperature at $Z_{\mathrm{b}}$, fifth column is the temperature at $Z_{\mathrm{t}}$, sixth column is the temperature gradient $m_{k}\left({ }^{\circ} \mathrm{C} / 100 \mathrm{~m}\right)$, seventh column is the depth of the layer $(\mathrm{m})$ and eighth column is the layer classification.

\begin{tabular}{|c|c|c|c|c|c|c|c|}
\hline Layer & $Z_{\mathrm{b}}(\mathrm{m})$ & $Z_{\mathrm{t}}(\mathrm{m})$ & $T_{\mathrm{b}}\left({ }^{\circ} \mathrm{C}\right)$ & $T_{\mathrm{t}}\left({ }^{\circ} \mathrm{C}\right)$ & $m_{k}\left({ }^{\circ} \mathrm{C} / 100 \mathrm{~m}\right)$ & Depth (m) & Classification \\
\hline & \multicolumn{7}{|c|}{15 January 2014 00:00 UTC } \\
\hline 2 & 62 & 165 & -17.7 & -12.3 & 5.2 & 165 & SBI top \\
\hline 8 & 685 & 925 & -8.7 & -10.5 & -0.7 & 240 & EI \\
\hline \multirow[t]{2}{*}{13} & 1108 & 1751 & -7.9 & -12.1 & -0.6 & 643 & EI \\
\hline & \multicolumn{7}{|c|}{13 October 2009 15:00 UTC } \\
\hline 5 & 35 & 44 & 0.4 & 0.7 & 3.5 & 44 & SBI top \\
\hline 12 & 256 & 289 & 2.9 & 3.2 & 0.8 & 33.1 & EI \\
\hline 15 & 371 & 425 & 3.8 & 4.3 & 0.7 & 53 & EI \\
\hline 18 & 499 & 541 & 3.92 & 3.93 & 0.01 & 41.3 & EI \\
\hline 20 & 615 & 654 & 3.8 & 4.3 & 1.0 & 39.2 & EI \\
\hline 30 & 1069 & 1098 & 5.4 & 5.7 & 0.99 & 28.5 & EI \\
\hline 32 & 1157 & 1213 & 5.5 & 5.7 & 0.35 & 56 & EI \\
\hline 36 & 1484 & 1530 & 5.5 & 5.6 & 0.03 & 46 & EI \\
\hline 41 & 1907 & 1983 & 4.1 & 4.3 & 0.23 & 76 & EI \\
\hline 47 & 2346 & 2383 & 2.8 & 3.3 & 1.34 & 37 & EI \\
\hline
\end{tabular}

In order to summarize the application of this methodology and visualize the effects of the final error over the reconstructed temperature profile, Fig. 6 illustrates the resampled temperature profile based on the case of four selected error levels for both cases.

It is clear that the lowest error (\%) is associated with lowering the convergence factor $\varepsilon$, while on the other hand increasing the preset convergence factor $\varepsilon$ increases the overall temperature retrieved error; therefore, the fine structure in the temperature profile vanishes. This is very important to consider. For example, for more than $10 \%$ of error the entire ABL thermal structure of local forcing disappears indicating just the presence of the EI layers. 

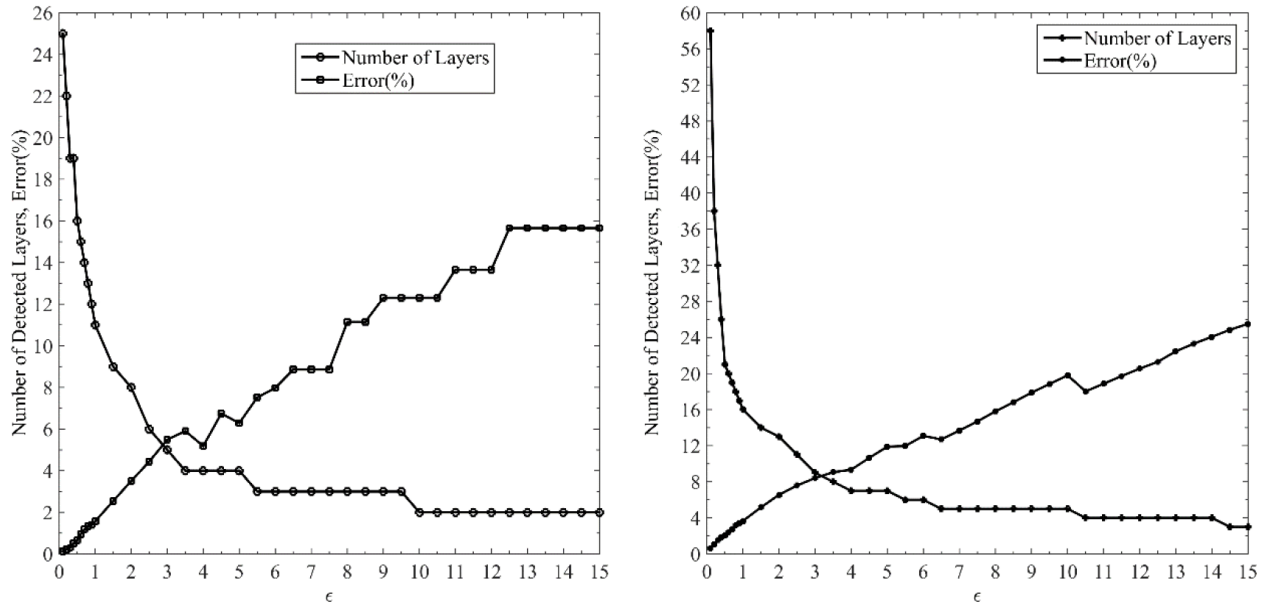

Figure 5. Retrieved number of thermal layers (o) and final temperature profile error ( $\square$ ) as function of the $\varepsilon$ convergence preset value. Panel on the left corresponds to 15 January 2014 at 00:00 UTC and panel on the right corresponds to 13 October 2009 at 15:00 UTC.
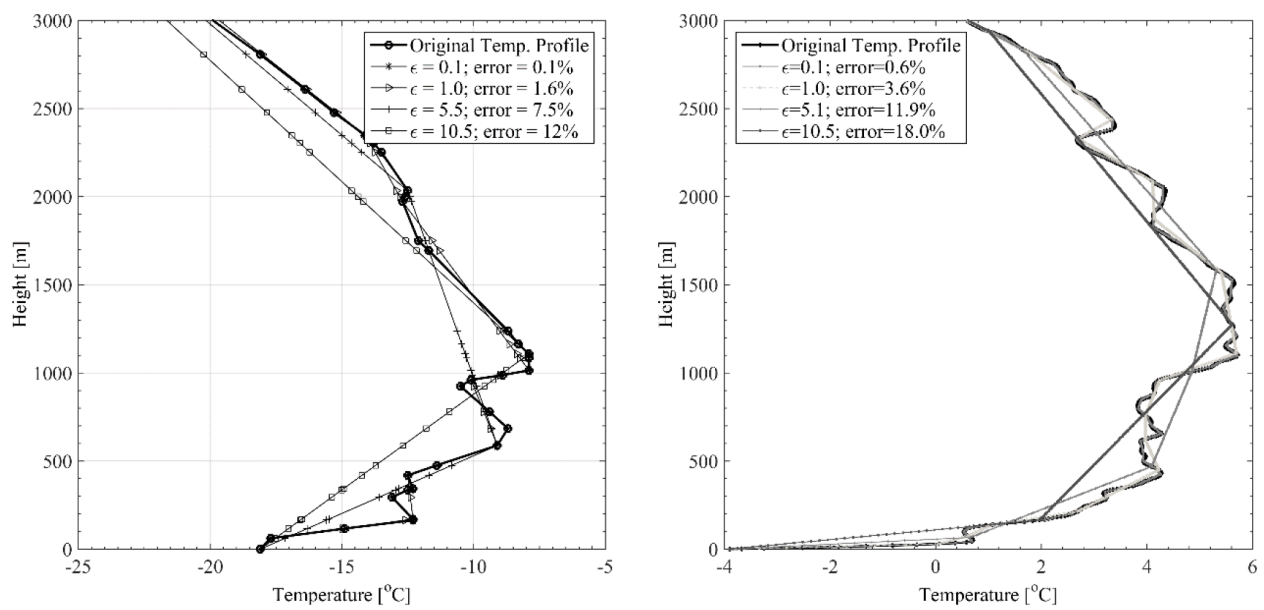

Figure 6. Resampled temperature profile after running the numerical methodology over different preset convergence factor values $\varepsilon=$ 0.1, 1.0, 5.5 and 10.5 as function of the final retrieved error (\%). Panel on the left is for 15 January 2014 at 00:00 UTC and panel on the right is for 13 October 2009 at 15:00 UTC.

\section{Summary}

A simple numerical iterative routine was developed to deduce thermal inversion layers composing a given atmospheric temperature profile. The numerical routine converts the temperature profile in a reduced data structure containing base and top heights and temperatures as well as thermal gradients allowing identification of most important air mass changes accounting for surface-based inversion (SBI) and elevated inversions (EI) present in the temperature sounding.

This methodology has been applied to the study of 10 years of upper air data in the interior of Alaska to deduce the statistical significance of the presence of SBI and multilevel EIs. In addition, the application of this methodology allowed classification of EI layers based on the type of synoptic air mass by means of the dew-point temperature gradient across the inversion layer depth (Mayfield and Fochesatto, 2013).
The method was also applied to study the temporal evolution of SBIs using high-resolution GPS soundings during the formation and breakup cycle in spring and fall seasons (Malingowski et al., 2014).

The method does not introduce new temperature points; it rather reduces the number of them according to the preset convergence factor. After the data structure is obtained, the determination of temperature inversion layers follows the search of changes in the $m_{k}$ coefficient.

Based on this methodology temporal series of temperature inversion height can be formed analyzing the data structure output and, after applying a specific set of criteria, identify a time series of a particular nature. For example, in Mayfield and Fochesatto (2013), the interest was to perform a statistical analysis of heights of SBIs and the presence of EI-1 to -4 layers. Using this numerical routine, it was possible to 
classify them in terms of their dew-point temperature gradient across the inversion depth. For that, it was necessary to include the dew-point temperature in the data structure after reading and processing the radiosonde data so that the retrieved EI layer could be classified.

The relationship between threshold thermal gradient $\mathrm{d} T / \mathrm{d} z$, the preset convergence factor $\varepsilon$ and the overall final error between the resample temperature profile and the original temperature profile is not straightforward. Section 3 describes the relationship between $\mathrm{d} T / \mathrm{d} z$ and $\varepsilon$ for a theoretical profile to deduce this relationship. Section 4 applies the methodology, and then a resampled version of the temperature profile was compared with the original temperature profile to calculate an overall percent error. This is important to differentiate since $\varepsilon$ applies internally as a convergence factor to increase fidelity in the temperature fitting process over a Euclidean norm that applies over a variable vector length step by step. On the other hand, the overall error indicating how accurate the resampled temperature profile reproduces the original profile accounts for the entire profile at once.

The application of such methodology has numerous venues. For instance, air pollution meteorology and pollutant transport processes are strongly dependent on meteorological conditions near the emission source - in particular at high latitudes where the SBI layers and stratified SBI show a persistent presence during the winter in the absence of or under a little diurnal cycle. The application of this methodology is not restricted to low-level layers exclusively since it has been demonstrated by Mayfield and Fochesatto (2013) that EI layers also play an important role in the high-latitude ABL because of the dynamic-radiative forcing that drives surface warming and pollutant recirculation. Another application is the evaluation of large-scale synoptic meteorological changes and their impact on high-latitude environments. In this case it is important to consider a methodology that can scrutinize thermal layers present in the temperature profile over ocean, maritime and continental places. In order to be able to evaluate the impact of prescribed synoptic meteorological patterns over a specific area, it is necessary to retrieve simultaneously thermal layers affected by local-scale and those dominated by large-scale atmospheric motion. Therefore evaluation of temporal series containing this multilayered information could assist in improving our understanding of how large-scale feedbacks are introduced and affect the local environment. Since the radiative interaction between SBI and EI layers is controlled by the vertical stratification, then the analysis of surface warming in high-latitude continental and oceanic environments in particular over sea-ice surfaces will be one future application of this methodology. Of course databases in which the method can be applied need to have sufficient vertical resolution to pull level details close to the surface to be able to define the multilayered structure.

The algorithm was proposed for radiosonde profiles, but it can also process temperature outputs from microwave radiometers and large-scale reanalysis databases as well as cli- mate outputs downscaled to temperature profiles. Particularly interesting is the use of this algorithm in climatological determination of the temperature inversion layers SBI and EI and their connection to large-scale synoptic meteorology.

Acknowledgements. This research was funded by the Division of Air Quality from the Department of Environmental Conservation of Alaska and the Air Quality Office of the Fairbanks North Star Borough (funding number G00006433-398755). The author was supported by the Geophysical Institute, University of Alaska Fairbanks. The author acknowledge the use of the NOAA/ESRL reanalysis database. The author thanks Julie Malingowski for preparing and launching the high-resolution GPS soundings and the three anonymous reviewers for insightful comments that improved the article.

Edited by: G. Vulpiani

\section{References}

André, J. C. and Mahrt, L.: The nocturnal surface inversion and influence of clear-air radiative cooling, J. Atmos. Sci., 39, 864878, 1982.

Beyrich, F. and Weill, A.: Some Aspects of Determining the Stable Boundary-Layer Depth from Sodar Data, Bound.-Lay. Meteorol., 63, 97-116, 1993.

Bianco, L. and Wilczak, J.: Convective boundary layer depth: improved measurement by Doppler Radar wind profiler using fuzzy logic methods, J. Atmos. Ocean. Tech., 19, 1745-1758, 2002.

Billelo, M. A.: Survey of arctic and subarctic temperature inversions. US Army Cold Regions Research \& Engineering Laboratory, Hanover N. H., 36 pp., TR 161, 1966.

Bintanja, R., Graversen, R. G., and Hazeleger, W.: Arctic winter warming amplified by the thermal inversion and consequent los infrared cooling to space, Nat. Geosci., 4, 758-761, doi:10.1038/NGEO1285, 2011.

Bourne, S. M., Bhatt, U. S., Zhang, J., and Thoman, R.: Surfacebased temperature inversions in Alaska from a climate perspective, Atmos. Res., 95, 353-366, 2010.

Bowling, S. A., Ohtake, T., and Benson, C. S.: Winter pressure systems and ice fog in Fairbanks, Alaska, J. Appl. Met., 7, 961-968, 1968.

Brooks, I. M.: Finding Boundary Layer Top: Application of a Wavelet Covariance Transform to Lidar Backscatter Profiles, J. Atmos. Ocean. Tech., 20, 1092-1105, 2003.

Byers, H. R. and Starr, V. P.: The circulation of the atmosphere in high latitudes during winter, Mon. Wea. Rev. Supplement No. 47, 34 pp., 1941.

Cassano, E. N., Cassano, J. J., and Nolan, M.: Synoptic weather pattern controls on temperature in Alaska, J. Geophys. Res., 116, D11108, doi:10.1029/2010JD015341, 2011.

Clements, C., Whiteman C., and Horel, J.: Cold-air-pool structure and evolution in a mountain basin: Peter Sinks, Utah, J. Appl. Meteor., 42, 752-768, 2003. 
Csanady, G. T.: Equilibrium theory of the planetary boundary layer with an inversion lid, Bound.-Lay. Meteorol., 6, 63-79, 1974.

Curry, J. A.: On the formation of continental polar air, J. Atmos. Sci., 40, 2279-2292, 1983.

Eastman, R. and Warren, S. G.: Interannual Variations of Arctic Cloud Types in Relation to Sea Ice, J. Climate, 23, 4216-4232, 2010.

Fochesatto, G. J., Drobinski, P., Flamant, C., Guédalia, D., Sarrat, C., Flamant, P. H., and Pelon, J.: Observational and Modeling of the Atmospheric Boundary Layer Nocturnal- Diurnal Transition during the ESQUIF Experiment, in: Advances in Laser Remote Sensing, edited by: Dabas, A., Loth, C., and Pelon, J., 439-442, Paris, France, 2001a.

Fochesatto, G. J., Drobinski, P., Flamant, C., Guedalia, D., Sarrat, C., Flamant, P., and Pelon, J.: Evidence of Dynamical coupling between the residual layer and the developing convective boundary layer, Bound.-Lay. Meteorol., 99, 451-464, 2001 b.

Fochesatto, G. J., Ristori, P., Flamant, P. H., Ulke, A., Nicolini, M., and Quel, E.: Entrainment results in the case of strong mesoscale influences over the atmospheric boundary layer in the near coastal region, Peer reviewed contributions to the International Laser Radar Conference, 231-234, Québec, Canada, 2002.

Fochesatto, G. J., Ristori, P., Flamant, P. H., Machado, M., Singh, U., and Quel, E.: Backscatter LIDAR signal simulation applied to spacecraft LIDAR instrument design, Adv. Space Res., 34, 2227-2231, 2004.

Fochesatto, G. J., Collins, R. L., Yue, J., Cahill, C., and Sassen, K.: Compact Eye-Safe Backscatter Lidar for Aerosols Studies Urban Polar Environment, Proceedings of International Society for Optical Engineering, 5887, doi:10.1117/12.620970, 2005.

Fochesatto, G. J., Collins, R. L., Cahill, C. F., Conner, J., and Yue, J.: Downward Mixing in the Continental Arctic Boundary Layer during a Smoke Episode, Reviewed and revised papers presented at the Twenty-Third International Laser Radar Conference (ILRC), Nara, Japan, 24-28 July, 817-820, 2006.

Fochesatto, G. J., Mayfield, J. A., Gruber, M. A., Starkenburg D., and Conner, J.: Occurrence of Shallow Cold Flows in the Winter Atmospheric Boundary Layer of Interior of Alaska, Meteorol. Atmos. Phys., Springer, Vienna, Austria, 114, doi:10.1007/s00703-013-0274-4, 2013.

Garrat, J. R. and Brost, R. A.: Radiative cooling effect within and above the nocturnal boundary layer, J. Atmos. Sci., 38, 27302745, 1981.

Hartmann, B. and Wendler, G.: Climatology of the winter surface temperature inversion in Fairbanks, Alaska, Proceedings of the 85th Annual Meeting of the American Meteorological Society, San Diego, CA, 1-7, 2005.

Holmgren, B., Spears, L., Wilson, C., and Benson, C.: Acoustic soundings of the Fairbanks temperature inversions, in: Climate of the Arctic, edited by: Weller, G. and Bowling, S. A., Proceedings of the AAAS-AMS conference, Fairbanks, Alaska, 293306, 1975.

Huff, D. M., Joyce, P. L., Fochesatto, G. J., and Simpson, W. R.: Deposition of dinitrogen pentoxide, $\mathrm{N}_{2} \mathrm{O}_{5}$, to the snowpack at high latitudes, Atmos. Chem. Phys. Discuss., 10, 25329-25354, doi:10.5194/acpd-10-25329-2010, 2010.
Kahl, J.: Characteristics of the low-level temperature inversion along the Alaskan Arctic coast, Int. J. Clim., 10, 537-548, 1990.

Kahl, J. D., Serreze, M. C., and Schnell, R. C.: Tropospheric lowlevel temperature inversions in the Canadian Arctic, Atmos.Ocean, 30, 511-529, 1992.

Lammert, A. and Bosenberg, J.: Determination of the convective boundary-layer height with Laser Remote Sensing, Bound.-Lay. Meteorol., 119, 159-170, 2006.

Mahrt, L., Vickers, D., Nakamura, R., Sun, J., Burns, S., and Lenschow, D.: Shallow drainage flows, Bound.-Lay. Meteorol., 101, 243-260, 2001.

Malingowski, J., Atkinson, D., Fochesatto, G. J., Cherry, J., and Stevens, E.: An Observational Study of Radiation Temperature Inversions in Fairbanks, Alaska, Polar Science, 8, 24-39, 2014.

Mayfield, J. A. and Fochesatto, G. J.: The Layered Structure of the winter Atmospheric Boundary Layer in the Interior of Alaska, J. Appl. Meteorol. Clim., 52, 953-973, 2013.

Menut, L., Flamant, C., Pelon, J., and Flamant, P. H.: Urban boundary-layer height determination from lidar measurements over the Paris area, Appl. Opt., 36, 945-954, 1999.

Milionis, A. E. and Davies, T. D.: A five-year climatology of elevated inversions at Hemsby (UK), Int. J. Climatol., 12, 205-215, 1992.

Milionis, A. E. and Davies, T. D.: The effect of the prevailing weather on the statistics of atmospheric temperature inversions, Int. J. Climatol., 28, 1385-1397, 2008.

Overland, J. E. and Guest, P. S.: The Arctic snow and air temperature budget over sea ice during winter, J. Geophys. Res., 96, 4651-4662, 1991

Raddatz, R. L., Galley, R. J., Candlish, L. M., Asplin, M. G., and Barber, D. G.: Integral Profile Estimates of Sensible Heat Flux from an Unconsolidated Sea-Ice Surface, Atmos.-Ocean, 51, 135-144, doi:10.1080/07055900.2012.759900, 2013a.

Raddatz, R. L., Galley, R. J., Candlish, L. M., Asplin, M. G., and Barber, D. G.: Integral Profile Estimates of Latent Heat Flux under Clear Skies at an Unconsolidated Sea-Ice Surface, Atmos.Ocean, 51, 239-248, doi:10.1080/07055900.2013.785383, 2013b.

Robbins, C. C. and Cortinas, J. V.: Local and synoptic environments associated with freezing rain in the contiguous United States, Weather Forecast., 17, 47-65, 2002.

Seidel, D. J., Ao, C. O., and Li, K.: Estimating climatological planetary boundary layer heights from radiosonde observations: Comparison of methods and uncertainty analysis, J. Geophys. Res., 115, D16113, doi:10.1029/2009JD013680, 2010.

Serreze, M. C., Kahl, J. D., and Schnell, R. C.: Low-level temperature inversions of the Eurasian Arctic and comparisons with Soviet drifting station data, J. Climate, 5, 615-629, 1992.

Shulski, M. and Wendler, G.: The Climate of Alaska, University of Alaska, Fairbanks, 216 pp., 2007.

Stull, R.: An Introduction to Boundary Layer Meteorology, Kluwer Academic Publishers, Dordrecht, the Netherlands, 666 pp., 1988.

Ueno, H., Oka, E., Suga, T., and Onishi, H.: Seasonal and interannual variability of temperature inversions in the subarctic North Pacific, Geophys. Res. Lett., 32, L20603, doi:10.1029/2005GL023948, 2005. 
Whiteman, C. and Zhong, S.: Downslope Flows on a Low-Angle Slope and Their Interactions with Valley Inversions, J. Appl. Meteorol., 47, 2023-2038, 2008.

Zhang, Y. and Seidel, D. J.: Challenges in estimating trends in Arctic surface-based inversions from radiosonde data, Geophys. Res. Lett., 38, L17806, doi:10.1029/2011GL048728, 2011.
Zhang, Y., Seidel, D. J., Golaz, J.-Ch., Deser, C., and Tomas, R.: Climatological characteristics of Arctic and Antarctic surfacebased inversions, J. Climate, 24, 5167-5186, 2011. 